\title{
Improving the efficient and robust uncertainty quantification in real-time flood forecasting using Polynomial chaos expansions and ensemble Kalman filter
}

Tran Ngoc Vinh and Jongho Kim*

vinhtn@mail.ulsan.ac.kr and kjongho@ulsan.ac.kr

\section{Motivation in hydrologic flood forecasting}

$\square$ Quantifying the uncertain ranges due to many sources is indeed important but time consuming.

$\square$ Securing sufficient (golden) time plays a significant role in terms of flood warning and risk mitigation.

\begin{tabular}{|c|c|c|c|c|c|}
\hline \multirow{2}{*}{$\begin{array}{c}\text { Quantifying } \\
\text { Uncertainties }\end{array}$} & \multirow[t]{2}{*}{ VS } & \multirow{2}{*}{$\begin{array}{c}\text { Securing } \\
\text { golden time }\end{array}$} & $\begin{array}{l}\text { Dimension } \\
\text { (the number of } \\
\text { uncertain parameters) } \\
\end{array}$ & $\begin{array}{l}\text { Model runs required } \\
\text { (10 points per dimension) }\end{array}$ & $\begin{array}{l}\text { Time required in } 100 \text { cores } \\
\text { (30 CPP Minutes } \\
\text { per simulation }{ }^{2}\end{array}$ \\
\hline & & & 1 & 10 & 3 minutes \\
\hline \multirow{3}{*}{\multicolumn{3}{|c|}{$\begin{array}{l}\square \text { if } 30 \mathrm{~min} / \mathrm{run}, \sim 5.7 \text { years for } 10^{\wedge} 7 \\
\square \text { if } 30 \mathrm{sec} / \mathrm{run}, \sim 0.1 \text { years for } 10^{\wedge} 7 \\
\text { if } 30 \mathrm{~ms} / \mathrm{run}, \sim 50 \text { min for } 10^{\wedge} 7\end{array}$}} & 2 & 100 & 30 minutes \\
\hline & & & 3 & 1000 & 5 hours \\
\hline & & & 4 & 10000 & $\begin{array}{l}2 \text { d days } \\
\sim 75\end{array}$ \\
\hline
\end{tabular}
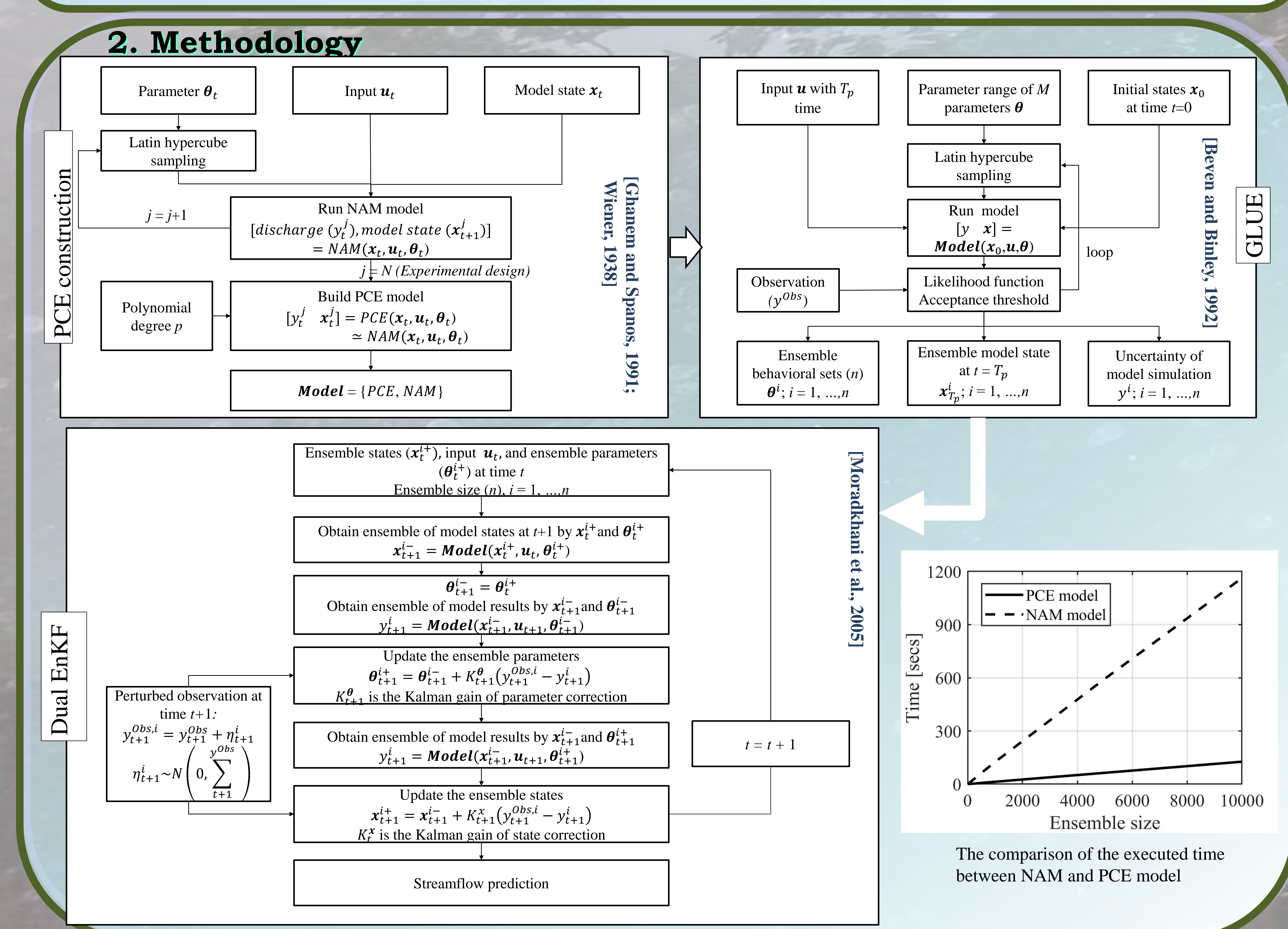

\section{Data and Scenarios analysis}

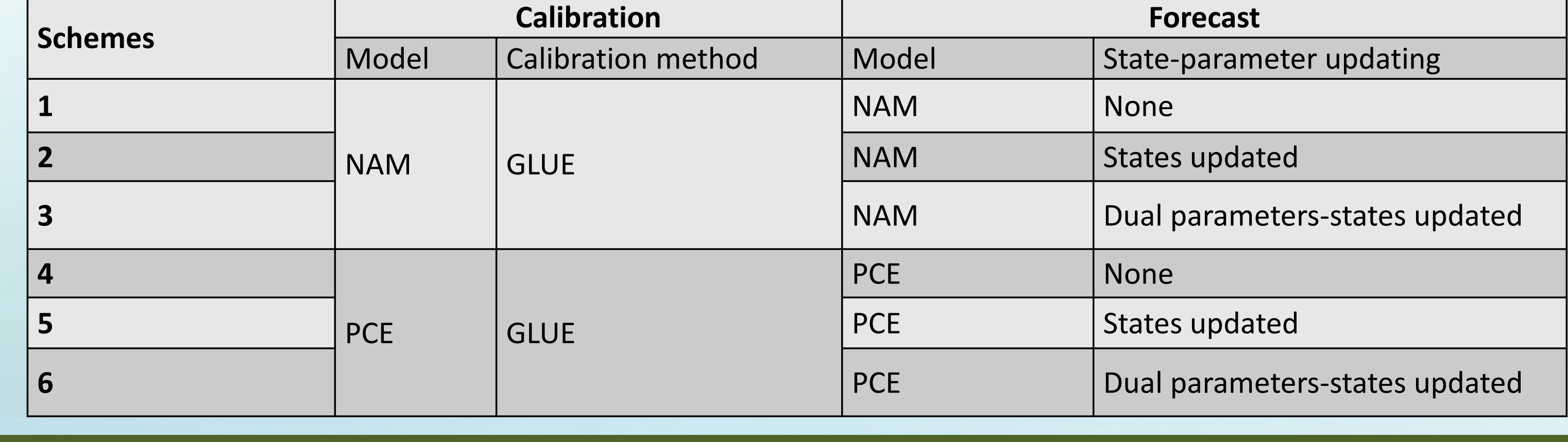

\section{PCE model construction}
Effects of Experiment Design $(N)$ \&
Polynomial degree $(p)$
Comparisons of results of MIKE-NAM vs. ment design, $N=1000$ and Polynomial Degree, $p=3$
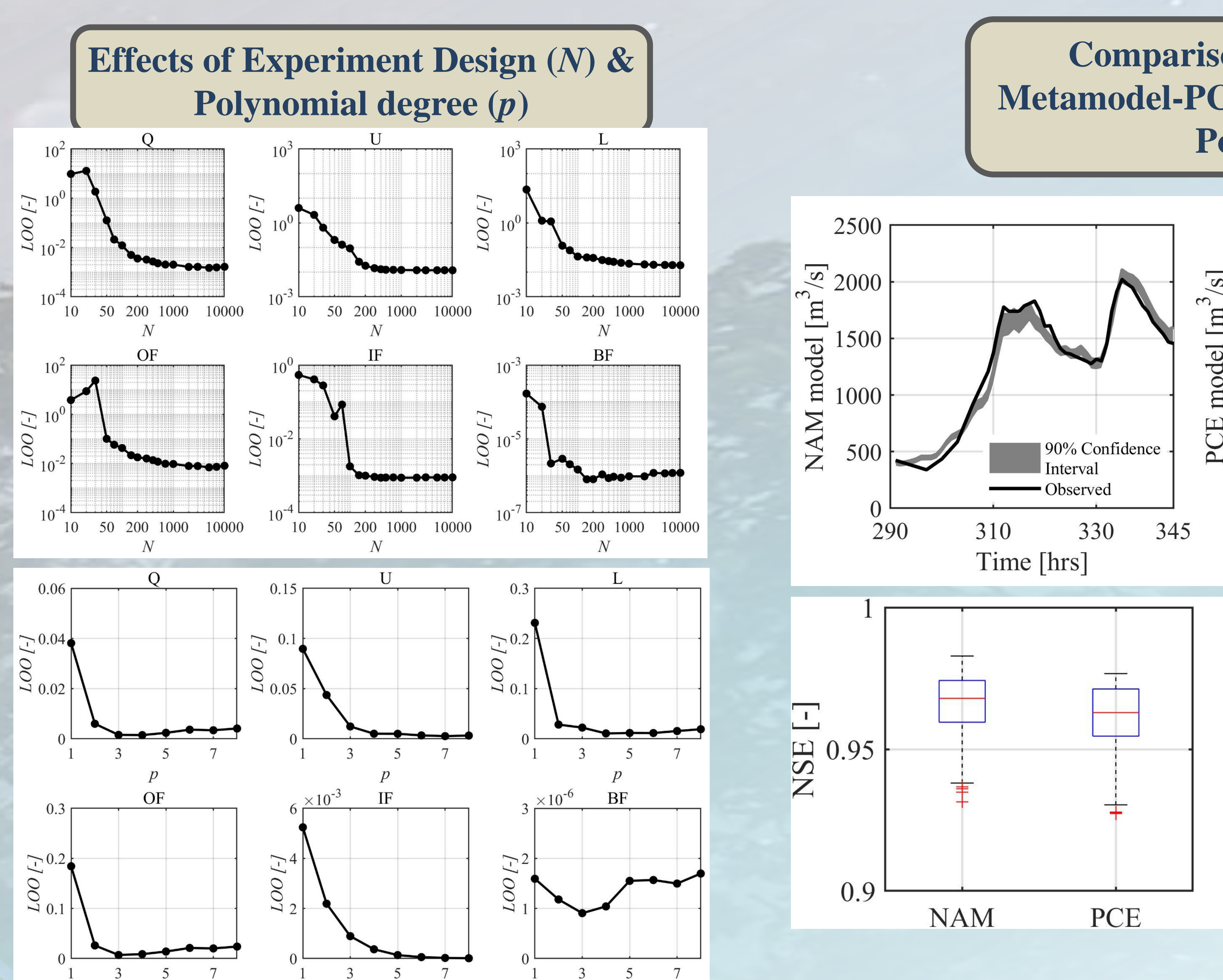

\section{Real-time flood forecasting based on PCE and Dual EnKF}

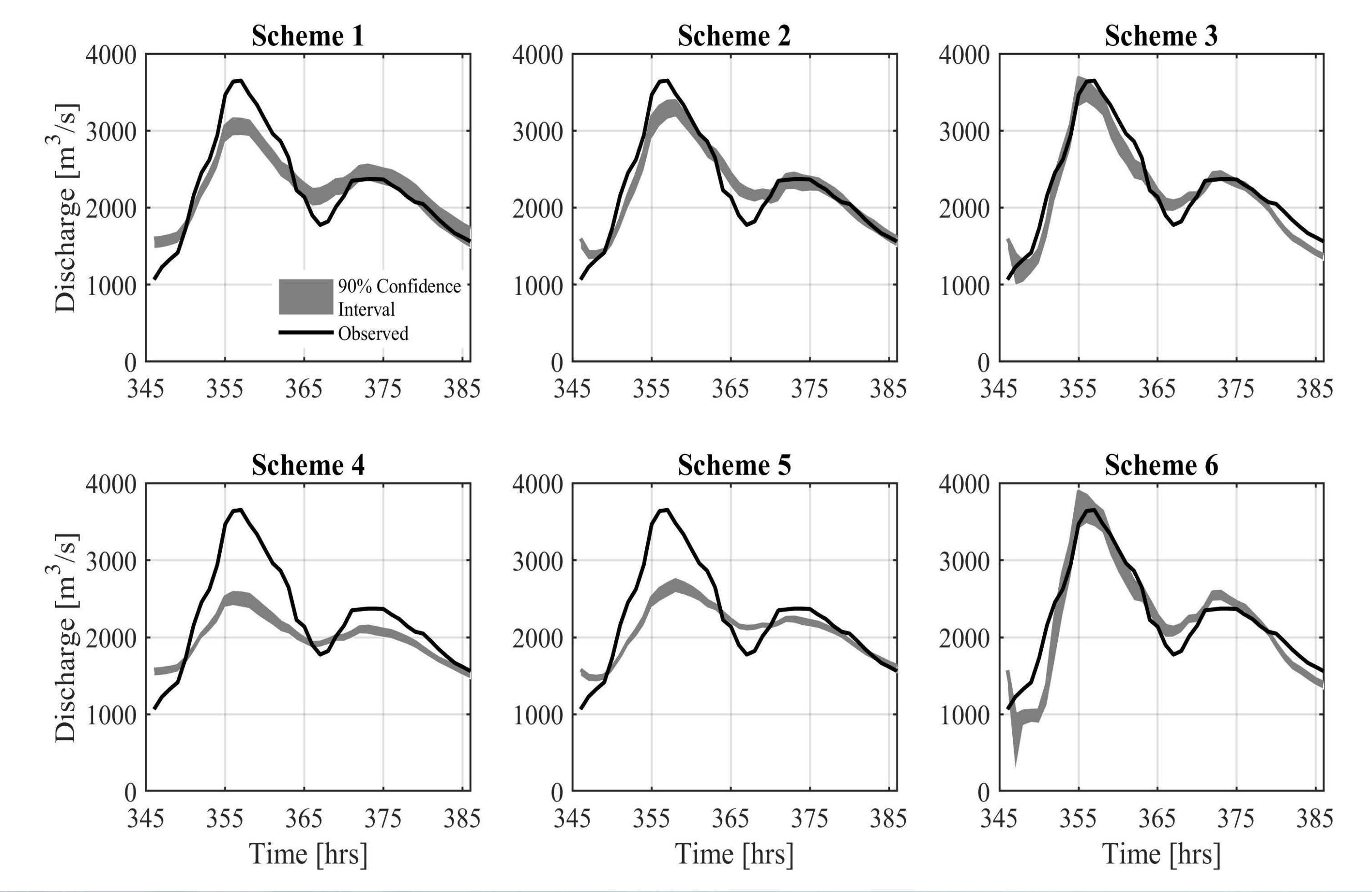

The result of model forecasting in real-time; Scheme 1 and 4 are NAM model and PCE model; Scheme 2 and 5 are NAM model and PCE mode with updated state state updated using Dual-EnKF

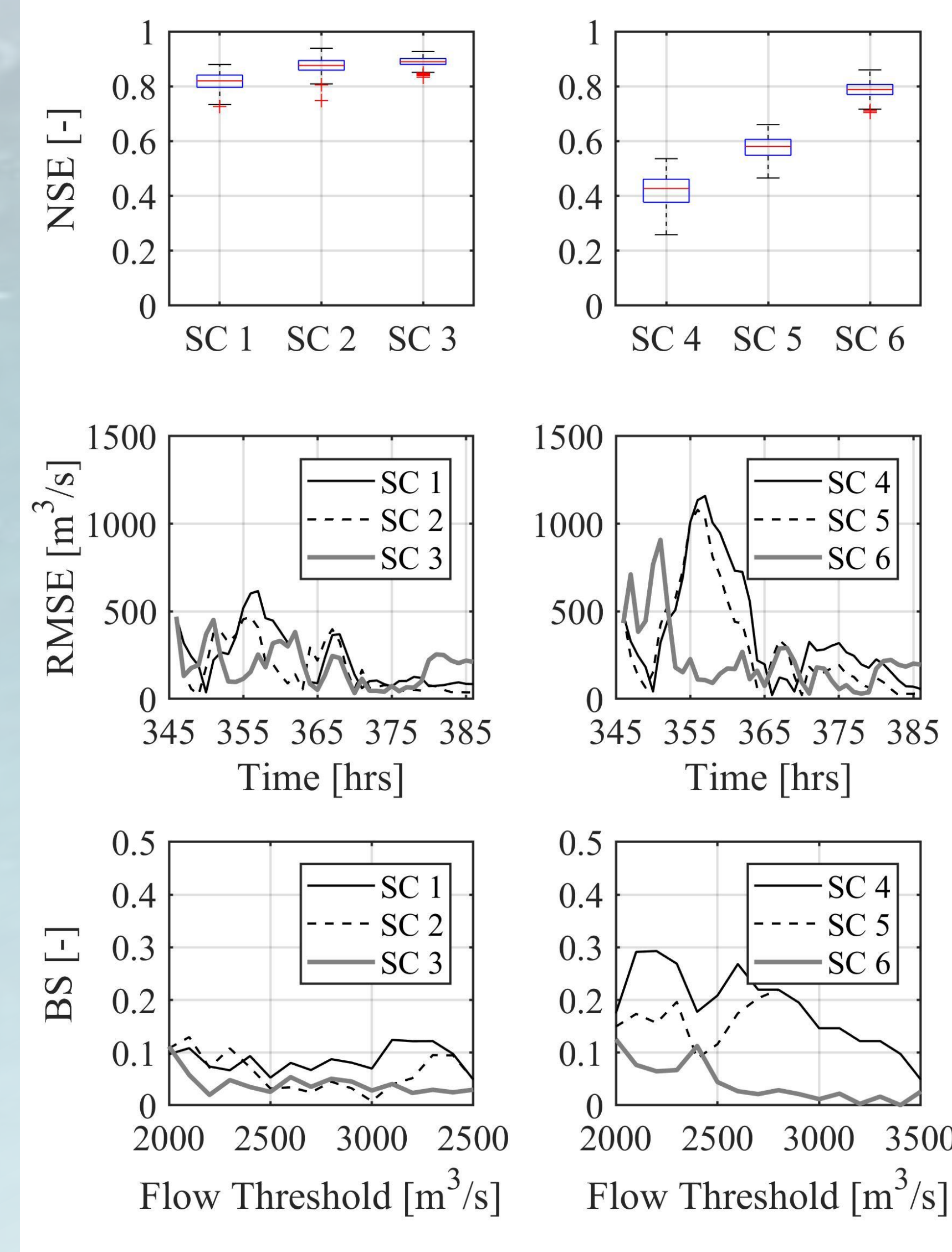

The verification of model forecasting, SC means $\mathrm{Sct}$

\section{Conclusions}

PCE model is able to efficiently quantify uncertainties caused by many sources with ten time faster than NAM model

The GLUE method can be used to generate the initial input for EnKF to imprive efficient of forecasting $\square$ Results forecasted with a metamodel based on PCE method are as good as those by MIKE-NAM modelthrough automatic updating of states and parameters by EnKF 